\title{
Comment
}

\section{Think globally, act locally}

Ommatidia appear to use the morphogenetic furrow for anteriorposterior information (the furrow is assumed to be initiated in the posterior of the disc) and for dorsalventral information (the furrow is assumed to be initiated in the dorsalventral midline). Both are potentially sensed through short-range cell interactions $9.11,12$, providing an excellent example of how local interactions can create a long-range pattern. The important thing seems to be that a firing centre provides an initial asymmetry, from which a pattern would then propagate outwards, by morphogenetic furrow movement (anterior-posterior) and by shortrange signalling berween ommatidia (dorsal-ventral). It makes sense to use a feature whose polarizy is already defined, but the question now becomes: what decides that the morphogenetic furrow is initiated at the posterior midline? It could be that the initiation mechanism (which is largely unknown) responds to a global $\mathrm{co}^{-}$ ordinate system in the disc. Alternatively, it could be induced by yet another prior feature in the disc, such as the nearby optic stalk (Fig. 1c).

\author{
References \\ I Dietrich, W. (1909) Z. Wiss. Zool. 92 , \\ $465-539$ \\ 2 Lawrence, P.A. (1992) The Making \\ of a Fly. Blackwell Scientific \\ 3 Heberlein, U., Wolff, T. and \\ Rubin, G.M. (1993) Cell 75. \\ 913-926 \\ 4 Ma, C.. Zhou, Y., Beachy, P.A. and \\ Moses, K. (1993) Cell 75, 927-938
}

5 Heberlein, U., Singh, C.M., Luk, A.Y. and Donohue, T.J. (1995) Nature $373,709-711$

$6 \mathrm{Ma}, \mathrm{C}$. and Moses, K. (1995) Development 121, 2279-2289

7 Pan, D. and Rubin, G.M. (1995) Cell $80,543-552$

8 Strutt, D.I., Wiersclorff, V. and Mlodzik, M. (1995) Nature 373 705-709

9 Wehrli, M. and Tomlinson, A. (1995) Development 121, 2451-2459

10 Chanut, F, and Helsertein, U. (1995) Development 121, 4085-4094

11 Strutt, D.I. and Mlodzik, M. (1995) Development 121, 4247-4256

12 Zheng, L., Zhang, J, and Casthew, R.W. (1995) Detelopment 121, 3045-3055

13 Gubb, D. (1993) Detelopment (Suppl.), 269-277

14 Wolff, T. and Ready, D.F. (1991) Development $113,841-850$

\section{Position effects and genetic disease}

\author{
ERIC MILOT, PETER FRASER AND FRANK GROSVELD* \\ * vanderkamp@ichl.fgg.eur.nl \\ The Erasisis Uxirkstr, MGC-Departmant of CFu. Biology and Genftics, PO Box 1738, \\ 3000 DR ROTTERDAM, THE NETHERIANTS.
}

The regulation of gene transcription is achieved by different levels of control. Most of the work in recent years has concentrated on the characterization of factors that act on proximal and distal DNA elements, which are responsible for the specific expression of a gene. Much less attention has been paid to the chromatin aspects of gene control. Recently, these two fields are rapidly starting to merge.

\section{Position effects}

The eukaryotic genome can be roughly divided into two cytologically distinguishable states: euchromatin and heterochromatin 1.2. The euchromatin regions are decondensed in interphase. They replicate early and contain mostly single-copy sequences and genes. In contrast, the heterochromatin regions remain condensed throughout the cell cycle, usually replicate late and contain a high proportion of middle-repetitive and highly repetitive sequences ${ }^{3}$. Exactly how the state of chromatin modulates gene expression is still largely unknown, although it is very clear that the chromatin is not simply a passive structural scaffold ${ }^{4}$.

Position effects (PEs), that is, a change in the expected level of gene expression, have been associated with integration or transiocation of a gene with other regions of the genome. In some cases, heterochromatic and euchromatic regions can be juxtaposed, and this can cause a change in expression of the genes located in the vicinity of the breakpoint 5

One particular type of $\mathrm{PE}$, first observed in Drosopbila and yeast, occurs through relocalization of a gene into a lieterochromatic environment, which leads to a shut-down of expression of the gene in some of the cells. This cell-to-cell mosaic expression could be created by a differential spreading of the heterochromatin. Tius phenomena, which is clonal and heritab!e in daughter cells, is known as po ition-effect variegation (PEV; Rei. 6) and has yet to be explained fully at the molecular level.
This effect can be altered by the products of a number of genes known as enhancers or suppressors of PEV, which are proteins that are thought to change chromatin packaging. The spreading of such factors into neighbouring areas that contain the relocalized gene is thought to modulate the ability of transcription factors to bind their target DNA sequences. This is strongly supported by studies on telomeric silencing in yeast. Gene suppression is reduced by mutations occurring in SIR2, SIR3, SIR4, NAT1, ARD1 and RAP1, which encode factors that bind to telomeric regions ${ }^{7}$. Other spatial effects on gene expression have been observed and correlated to the presence of these proteins. For example, $R A P 1$ is known to be present at high concentration in spots near the nuclear envelope ${ }^{8}$ and is proposed to be involved in the repression of genes in these areas of the nucleus. Suppression by reducing accessibility of the trans-acting factor(s) can be monitored by the inability to methylate telomeric sequences 9 


\section{COMment}

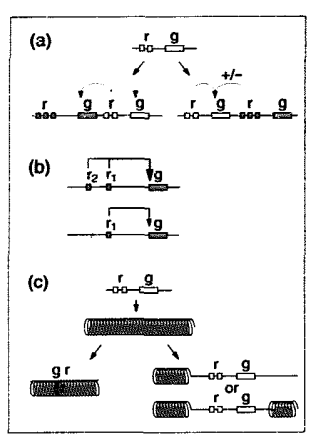

FiguRE 1. Different types of position effects. (a) An incoming (open boxes) gene $(\mathrm{g})$ and distal regulatory elements $(\mathrm{r})$ integrate next to resident gene or regulatory elements (grey boxes). Dotted

line represents decreased frequency of interactions due to competition from the resident gene. $+/ /-$ indicates that interactions between resident regulatory elements and the incoming gene could have positive or negative effects on transcription. (b) A resident gene with multiple, distal regulatory elements undergces a deletion or translocation resulting in the juxtaposition of two originally non-adjacent chromatin regions. Differences in expression could be explained by the loss of a regulatory element. (c) An incoming gene with distal regulatory elements integrates into a region

of heterochromatin. This could result in

shurdown of the gene (blick) through heterochromatinization or maintenance of an open chromatin structure of the gene through interaction with dominant. positive regulatory clements.

and can be counteracted by an increased concentration of a transcription factor whose targer sequence is in the telomeric region ${ }^{10}$. Hence, suppression versus activation appears to b.: regulated by an equilibrium between (specific) positively acting factors and general negatively acting chromatin-binding proteins.

A completely different type of position effect can be envisaged when a gene and its regulatory regions end up next to another gene as a resuit of a genomic rearrangement (Fig. 1a). If the regulatory regions can interact with the other gene, then this will result in a competition between the genes, so that the original gene would be expressed at a lower level. Alternatively, the gene might end up next to a novel regulatory region that could up- or downregulate its expression (Fig. 1a). Either way, such an effect could be described as a regulatorposition effect (RPE), and would be seen as a change in the leve! of expression in a population of cells and in each single cell. However, when measured at the gene level in single cells ${ }^{11}$, it might show a change in the frequency of transcription (see below).

A different type of position effect can be envisaged when a deletion or rearrangement (and these could be a large distance from the gene) removes part or all of the regulatory regions of a gene (Fig. 1b). This could be called a deletion-position effect (DPE), and would result in a change in expression in each cell.

Chromatin-mediated silencing in competition with activation as observed in PEV (Fig. 1c and see above) can often be distinguished from RPE and DPE, because this effect appears at the level of a single cell in an all-or-none phenomenon, that is, the relevant gene is on or off. When viewed from a population of cells it is measured as an overall decrease, or even complete silencing. of expression. These three types of PE could be fundamentally different or be variations on a theme.

\section{Natural PE in mammals}

It is known that RPE exists in mammal: and that this can cause disease. One of the best examples is the coupling of the regulatory regions of the immunoglobulin genes to the MYC oncogene in Burkitt's lymphoma. This novel combination of gene and regulator results in inappropriate $M Y C$ expression ${ }^{12}$

As would be expected, DPE also exists in mammals. An example of DPE is that the deletion of the locus control region of the $\beta$-globin locus leads to inactivation of the $\beta$-globin genes up to $50 \mathrm{~kb}$ downstream. It is not obvious whether PEV plays a role in disease. However, a number of recent reports have changed this picture.

The first example is the study of a chromosomal disorder associated with campomelic dysplasia (CD), and autosomal sex reversal. The alteration of the chromosomal lous SRAI (17q25.1-q24.1) can lead tu failure in testis development and sex reversal, and to $C D$, a disease characterized by bone malformations ${ }^{13}$. This locus contains the SOX9 gene, which encodes a member of the SOX family of DNA-binding proteins. The SOX family encodes proteins that contain an AMG box and includes the sex determining gene $S R Y$. Foster et al. ${ }^{14}$ and Wagner et al..$^{15}$ have recently described a chromosomal rearrangement in the SOX9 locus of a patient having $C D$ and sex reversal. The breakpoint of this rearrangement is $88 \mathrm{~kb}$ from $S O X 9$. Examining this gene in other CD patients, they found that intemal mutations in the SOX9 coding region also lead to $C D$. There is no other gene known to be important for bone formation and for testis development in this locus. How, then, can a rearrangement $88 \mathrm{~kb}$ from SOX9 lead to CD? As the authors pointed out, it could be that some unidentified parts of $S O X 9$ are disrupted by the rearrangement. Another possibility is that the rearrangement led to silencing of SOX9because of a PE. This could be created by the novel environment of $50 \times 9$ in this rearrangement (PEV or RPE), but also by the deletion of important regulatory regions (DPE).

A similar observation was made for inactivation of the PAX6 gene, which, in the heterozygous state, leads to aniridia (absence of the iris) ${ }^{16}$. The analysis of two aniridia families revealed genomic rearrangements in the locus $11 \mathrm{p} 13$ containing the PAX6 gene $^{17}$. Precise mapping of the:ie genomic alterations showed that the chromosomal breakpoints are located at least $85 \mathrm{~kb}$ distal from the $3^{\prime}$ end of PAX6. Again, th:ese results could be explained as an extreme PEV, in which the new chromatin environment leads to complete silencing of PAX'6 in the chromosomal rearrangements. Alternatively, the results could be explained simply as a loss of an unidentified, distant regulatory region. Another recent exarnple of a disease with a possible PE concerns the POU3F4 gene, which is involved in $\mathrm{X}$-linked deafness ${ }^{18,19}$.

The last exampic was obtained in a study of the Steel ( $S l$ ) locus in mice. The $\mathrm{Sl}$ locus is essential for the development of germ celis, haematopoietic cells and melanocytes ${ }^{20}$. The gene encodes the mast-cell gronth factor, MGF, which is the ligand of the tyrosine kinase receptor encoded by kit. The molecular defects in two $\mathrm{Sl}$ mutant 


\section{Comment}

alleles that lead to sterility in females were shown to be chromosomal rearrangements ${ }^{21}$. As in the cases for SOX9and PAX6described above, the reamangements were mapped precisely with breakpoints at 115 aid $195 \mathrm{~kb}$ from the $\mathrm{Mg} f$ coding region. In both reamangements, $M g$ franscripts seem to be normal but the level of expression is altered by the rearrangements. Again, this suggests that the new environment of the $M g f$ coding region could affect the level of expression. but it could equally well be due to a loss of regulatory regions.

These three reports show that PE in mammals can play a role in genetic diseases. Although it is attractive to suggest that PEV is the cause, it is actually not clear because RPE or DPE could also be the cause of the phenotypes described above. In fact, all PEs could be interrelated and could be the different outcomes of affecting the balance between activation and suppression. The data supporting this idea have been obtained from transgenic mouse experiments.

\section{Transgenic PE in mammals}

PEs have been frequently observed in transformation systems and transgenic animals'. These pose significant problems in the study of gene regulation. However, studies on the human $\beta$-globin gene locus led to the discovery of the locus control region (LCR) which overcomes $\mathrm{PE}$ (Ref. 22). Since then, a number of other ICRs have been identified ${ }^{23}$. Similar to most regulatory elements, LCRs are tissue specific. However, they differ from common regulatory elements because they enable expression independent of the position of integration in the host genome. In addition, they provide a level of espression dependent on the number of copies of the LCR-transgene construct. The $\beta$-globin LCR is one contiguous piece of DNA of $21 \mathrm{~kb}$, which contains five tissue-specific hypersensitive sites 23.24 . In other cases, different numbers of hypersensitive sites have been found and they need not be immediately adjacent to each other. The hypersensitive regions bind to transcription factors and tíe suggestion is that this binding is responsible for the open chromatin configuration. This nould partly explain why euchromatic, but not heterochromatic, regions of the genome are sensitive to DNasel.
Another explanation for the prevention of $\mathrm{PE}$ would be provided by domain boundaries. This comes from the notion, originally based on cyto. logical data 25,26 , that genes or sets of genes de present in distinct domains separated by boundaries ${ }^{27}$. Two such candidate domain boundaries, scs and scs', were identified in Drosophila $^{28}$. These elements are characterized by a nuclease-resistant sequence (250-350bp) flanked by a pair of nuclease-hypersensitive sites. The nuclease-hypersensitive sites can insulate a reporter gene from $\mathrm{PE}$ in Drosopbila ${ }^{29}$. The hypersensitive site ( 5 'HS4) from the chicken $\beta$-globin locus was also reported to act as an insulator when tested in Drosopbila ${ }^{30}$. In contrast, we failed to finc' such activity in transgenic mice using the Drosophila scs elements or the human counterpart of chicken $5^{\prime} \mathrm{HS} 4$ (i.e. human HS5; Ref. 24).

There have been some reports of $P E$ in transgenic mice when LCR sequences are used in the construct $^{31-34}$. In one transgenic line reported by Strouboulis et al. ${ }^{32}$, all of the human transgenes in the locus were expressed at a lower level. This was probably caused by integration next to an endogenous gene that competes with the globin genes for the interaction with the LCR (i.e. a case of RPE). When prediciable levels of expression are required (e.g. in gene therapy), it would, therefore, be important to keep the distance between the promoter and the regulators as small as possible and, thus, lower the risk of RPE

One study using LCRs shows PEV (Ref. 33), and two other siulles discuss PE in general ${ }^{31.34}$. In these three cases, the LCRs used were incomplete or modified. The PEV observed by Elliott et al. ${ }^{33}$ occurred when the $\mathrm{CD} 2$ LCR is used in combination with the immunoglobulin enlancer, but not when the CD2 LCR is used alone ${ }^{35}$. Bonifer et al..$^{31}$ and Robertson et al ${ }^{34}$ used an LCR containing one or more hypersensitive sites 36.37 . Although no firm conclusions can be made from these results, they suggest that interference with an LCR, in the form of deletions or additions, make it sensitive to PEs.

Hence, deletions of the CD2 and the $\beta$-globin LCR were made and rested in transgenic mice ${ }^{36}$ (E. Milot et al., unpublished). In the case of the CD2 LCR, the deletion of the most $3^{\prime}$ hypersensitive site (HS3 downstream of the gene) yielded a number of mice with a classical, clonally heritable PEV. In the case of the $\beta$-globin LCR, the deletion of different hypersensitive sites was tested, and PE and PEV were borh found (E. Milot et al., unpublished).

The most interesting observation of both sets of experiments was the perfect correlation betwcen the observed effects and integration of the deletion constructs into heterochromatic regions of the host genome. Integration into euchromatin had no such effect. A possible explanation for these results, and those described above, comes from work describing the dynamics of globin LCR-gene interactions in viv ${ }^{11}$. The major implication from that work is that ICR-gene interactions are not st.tic, but that complexes form and dissociate continually. These stochastic interactions are dependent on three parameters: (1) the frequency of interaction, which is, itself, dependent on the distance of the gene to the LCR (Refs 39-41); (2) the affinity of the LCR for the gene; and (3) the stability of the LCR-gene complex. The latter two are dependent on the balance of DNA-binding proteins in the nucleus. The net conclusion is that the ICR determines, at least partly, the level of gene expression by determining the frequency of expression. In other words, the LCR would not increase the amount of polymerases that can be loaded on a gene at a given time but would, rather, increase the frequency of periods during which polymerases can be loaded on a gene 26 . It is easy to explain DPE and RPE in terms of the creation of novel combinations of regulatory elements and genes. It would appear to be more difficult to explain PEV and clonal inheritance, were it not for the fact that the cells in an apparently homogenous population are actually not transcriptionally identical at any given time ${ }^{11}$. Hence, a processive shut-down mechanism spre ading along the chromosome, as in heterochromatinization, might be in competition with a stochastic activation event. The net result of these two processes might not be the same in every cell and could result in a stable shut-down in some of the cells, which is inherited by an unknown mechanism through replication and division. The same percentage of expressing versus silent 
cells will be found in animals in the next generation because all the parameters underlying the stochastic events will be similar in the offspring to those in the parents.

In conclusion, studies of genetic diseases and transgenic models indicate that PE phenomena are important for mammalian gene regulation. Thus, genomic rearrangements should not be regarded as a tocal' reorganization of the genome only, but should also be regarded as events that could alter long-range chromatin interactions. At the moment, it is not clear whether DPE, RPE or PEV is the cause of the human diseases described above and, hence, whether PEV plays a role in mammalian disease at all. However. transgenic studies suggest that these different types of PE can be observed in mammals and that chromatin modulators, such as LCRs and domain boundaries, can be used to clarify the chromatin organization. Further molecular characterization of the diseases mentioned above, and others, should also help to understand the complexity of the organization of the mammalian genome. Some diseases are particularly gord candidates because of the chromosomal position of the gene(s) involved, such as the gene responsible for faciocapulohumeral muscular dystrophy, which is located close to the telomere of chromosome 4 (Ret. 42)

\section{References}

1 Heintz, E. (1928) lnt. Jabrh. Wiss. Bot. $69,762-818$

2 Eissenberg. J.C. Elgin, s.C.R. and Paro, R. (1995) in Chromati:? Struture and Gene Exyiession (Figin, SC. R., ed.). pp. 147-171. Oxford University Pres:

$3 \mathrm{John}, \mathrm{B} .(1988)$ in Heterochromatin: Holecular and Strictural Aspects
(Verma, R.S., ed.), pp. 141-147. Cambridge University Press

4 Pillus, L. and Grunstein, M. (1995) in Cbromatin Siructure and Gene Expression (Elgin, S.C.R., ed.), pp. 123-146, Oxford Liniversity Press

5 Wilson, C., Hugo, G., Bellen, $H$. and Gehring, W. (1990) Anntu. Rev. Cell. Biol. 6, 679-714

6 Karpen. G.H. (1994) Curr. Opin. Genet. Dev. 4, 281-291

7 Palladino, F. and Gasser, S.M. (1994) Curr. Opin. Cell Biol. 6, 373-379

8 Palladino, F. et al. (1993) Cell 75. 531-542

9 Gottschling, D.E. (1992) Proc. Natl Acad. Sci. USA 89, 4062-4065

10 Aparicio, O.M. and Gottschling, D.E. (1994) Genes Dev. 8, 1133-1146

11 Wijgerde, M., Grosveld. F. and Fraser. P. (1995) Nature 377. 209-213

12 Joos, S. et al. (1992) Hum. Mol. Genet. 1, 625-632

13 Tommerup. N. et al (1993) Nat. Genet. $4,170-174$

14 Foster, J.W. et al \{1994) Nature 372, $525-530$

15 Wagner, T. of al. (1994) Cell 79. 1111-1120

16 Ton, C.C.T. et al. (1991) Cell67, 1059-1074

17 Fantes, J. ef al. (1995) Hum. Mol. Genet. 4. 415-422

18 de Kok, Y.J.M. et al. (1995) Science 267. 685-688

19 de Kok, Y.J.M. et al. (1995) Hum. Afol. Genet. 4. 2145-2150

20 Silvers, W.K. (1979) The Goat Culon of Hice: A Model for Hammalian Gene Action and interaction, Springer-Verlag

21 Bedelf, M.A. et al (1995) Genes Det: 9. $455-470$

22 Grosveld, F., van Assendeift. G.B.. Greaves, D.R. and Kollias, G. (1987) Cell $51.975-985$

23 Dillon, N. and Grosveld, F. (1993) Trends Genet 9, 134-137

24 Zafarana, G. et al (1995) in toilume 1 of the Procesedings of the $9 t b$
Conference on Hemoglobin Stuitcbing (Stamatoyannopoulos, G. ed.), pp. 39-44

25 Gall, J. (1956) in Mutation, Brook-Haven Symp. Biol. 8, 17-26

26 Alfert, M. (1956) int. Rev. Cytol. 3 , 131-140

27 Schedl, P. and Grosveld, F. (1995) in Cbromatin Structure and Gene Expression (Elgin, S.C.R., ed.), pp. 174-196, Oxford University Press

28 Udvardy, A., Maine, E. and Schedl, P. (1985) J. Mol. Biol. 185, 341-358

29 Ketlum, R. and Schedl, P. (1991) Cell 64. 941-950

30 Chung. J.H., Whiteley, $M$. and Felsenfeld, G. (1993) Cell 74, 505-514

31 Bonifer, C. et al. (1994) Nucleic Acids Pes. 22, 4202-4210

32 Strouboulis, J., Dillon, N. and Grosveld, F. (1992) Genes Det. 6, 1857-1864

33 Elliott, J.1., Festenstein, R., Tolaini, M. and Kioussis, D. (1995) EMBOJ. 14. 575-584

34 Robertson, G. et al (1995) Proc. Natl Acad. Sci. USA 92. 5371-5375

35 lang, G. et al. (1988) EMBOJ. 7. $1675-1682$

36 Philipien. S. et al (1990) EMSOJ. 9 $2159-2167$

37 Pruzir a, S. et al. (1991) Nuchisic Acids Res. 9, 1413-1419

38 Festenstein. R. et al. Science (in press)

39 Hanscombe, O. et al (1991) Genes Dev. $5,1387-1394$

40 Pederson, K.R. and Stamatoyannopoulos, G. (1993) Mol. Cell. Biol. 13. 4836-4843

41 Dillon, N., Strouboulis, J. and Grosveld, F. in Molecular Biology of Hemoglobin Sutching: Proceedings of the 9 th Conference on Hemoglobin Suitching (Stamatoyannopoulos, G.. ed.), (in press)

42 Zatz, M. el al (1995) Am. f. Hum. Genet. 56, 99-105

\section{Included in the May issue of TIG}

\section{Olfaction in Drosopblla: from odor to behavior by Jobn R. Carlson}

Complications and implications of tinear bacterial chromosomes by Carton $W$. Cben

Control of messenger RNA stability in higher eukaryotes by Jeff Ross

Creating conditional mutations in mammals by David $M$. Spencer

\section{Xeroderma pigmentosum, Cockayne syndrome and trichothiodystrophy: do the genes explain the diseases? by Gilben Cbu and L;nne Mayne}

Puzaling out the genetics of anammalian sex determination

by Rafael Jimênez, Antonio Säncbez, Miguel Bungos and Rafael Diaz de la Guardia

Gene expression: incressing evidence for a transcriptosome

by Jörn-Peter Halle anḋ Micbael Meistenernst 